\title{
Fatigue and dwell-fatigue behavior of nano-silver sintered lap-shear joint at elevated temperature
}

\author{
Yansong $\operatorname{Tan}^{1}$, Xin $\mathrm{Li}^{2}$, Chengjun $\mathrm{Li}^{1}$, Xu Chen ${ }^{1, *}$ \\ ${ }^{1}$ School of Chemical Engineering \& Technology, Tianjin University, Tianjin 300072, China \\ ${ }^{2}$ School of Material Science and Engineering, Tianjin University, Tianjin 300072, China \\ * Corresponding author: xchen@tju.edu.cn
}

\begin{abstract}
Load-controlled fatigue and dwell-fatigue tests were conducted at elevated temperature to describe the high temperature behavior of nano-silver sintered lap-shear joints. The results show that the shear strength of nano-silver sintered lap-shear joints are strongly temperature dependent, and almost halved at the temperature of $325^{\circ} \mathrm{C}$. To describe the temperature effect on fatigue life under fully-reversed loading, Basquin's equation is developed by introducing temperature factor, and shows a good agreement with experiment results. In dwell-fatigue tests, creep is found the main factor resulted in failure acceleration and cyclic life reduction.
\end{abstract}

Keywords lap-shear, fatigue, dwell-fatigue, Basquin' equation, temperature dependent

\section{Introduction}

Nowadays, the use of tin-lead solder in certain application has been banned for its damage on healthy. However, there still are some fields such as power electronics packaging using high lead solder as interconnected material [1], which can be mainly attributed to the absence of appropriate substitution. Therefore, the introducing of environmental friendly die-attaching material becomes more and more important due to increasing stringent requirements of weight reduction, size miniaturization, high thermal dissipation, etc. [2].

In the 1970s, the view of diffusion welding silver film had been introduced by O'brien et al.[3], and thus a new die-attaching technology named low-temperature joining technology was remarkably promoted. With the assistance of mechanical pressure of about 40MPa, micro-sized silver powder could be sintered at temperature below $300^{\circ} \mathrm{C}$ [4]. From then on, silver is used widely in microelectronic packages as a promising interconnection material between substrates and chips because of its superior electrical/thermal conductivity, high melting temperature $(1,233 \mathrm{~K})$, and good reliability. Though, for brittle silicon chips and ceramic substrates, the aided pressure might be destructive even slightest irregularities [5]. To raise the sintering driving force of this interconnection material, the paste formed by nano-sized silver powder, which gained the close attention of both scientists and power electronics engineers, was introduced by Lu et al [6].

Before the sintering technology coming into practical application, the processing profile and the property of nano-silver paste had been studied. In recent years, A low-temperature sintering profile with sintering temperature of $285^{\circ} \mathrm{C}$, heating rate of $10^{\circ} \mathrm{C} / \mathrm{min}$, and holding time of 60 min was introduced by Wang et al [7]. Yu et al. studied the tensile behaviors of low-temperature sintered nano-silver films and proved that accumulation of plastic strain took place in silver-bonding layer during thermal cycling, which might lead to the final failure of the chip-attachment [8]. Chen et al. stated that the process of damage evolution of the nano-silver films was temperature independent by 
mass of creep test data at elevated temperatures [9]. However, these studies only revealed the properties of sintered silver film, which in turn imposed a limitation to consider the thermally induced strain due to thermal expansion coefficient mismatch between substrate and chip in actual applications. Li et al. $[10,11]$ constructed a lap-shear structure to study the mechanical property of sintered nano-silver as a joint. Following this lap-shear structure, further research on fatigue and dwell-fatigue property of sintered nano-silver joint was conducted in this study.

Not only tensile and fatigue tests but also creep-fatigue tests were conducted in this article in order to understand the failure mechanism of nano-silver sintered lap shear joint at elevated temperature, study any possible relation between creep and fatigue in the low-cycle regime and learn the probabilistic observed mechanisms The creep-fatigue tests were conducted at the temperature of $325^{\circ} \mathrm{C}$, at which both dwell time and fatigue process interacted and failure occurred in the low-cycle regime.

\section{Sample preparation and experiment procedure}

Details about lap-shear joint preparing have been presented elsewhere [11]. The well prepared sintered nano-silver structure with $2 \mathrm{~mm} \times 1 \mathrm{~mm} \times 50 \mu \mathrm{m}$ joint used in this study is showed in Fig. 1 . All the tests were conducted on Micro Uniaxial Fatigue Testing System (MUT-1020) provided by CARE Measure \& Control Co., Ltd. as shown in Fig. 2.

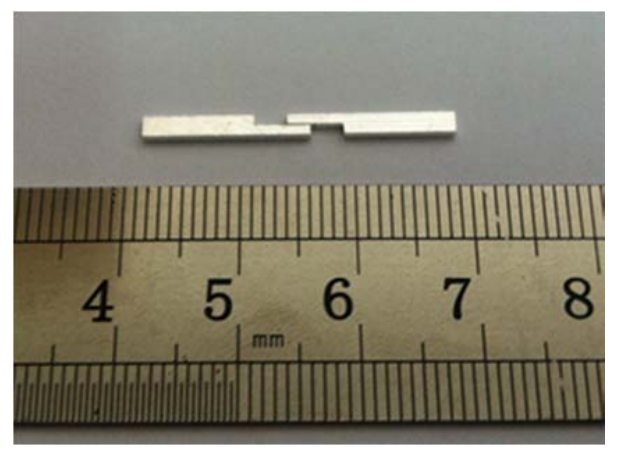

Fig. 1 Prepared sintered nano-silver lap-shear structure

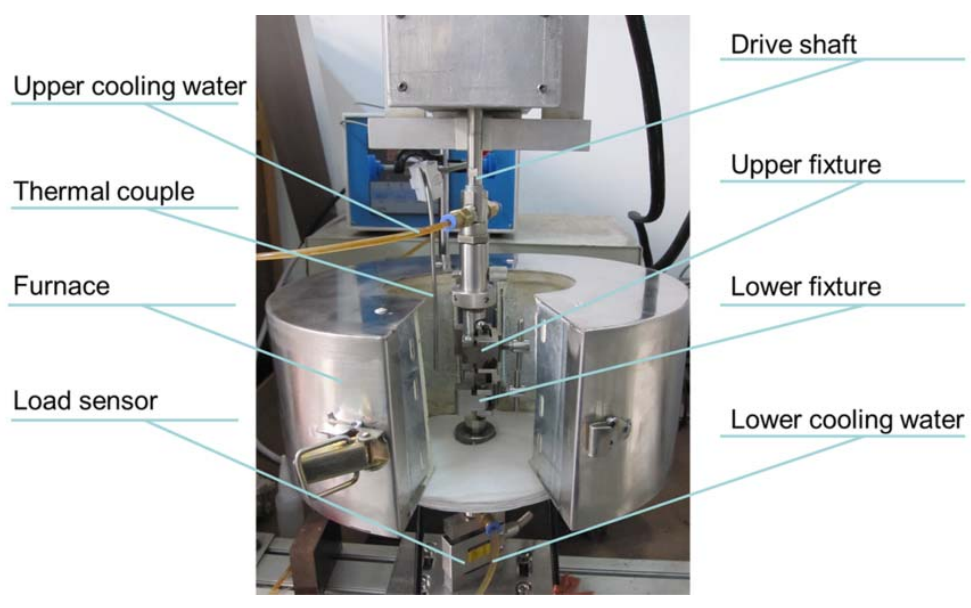

Fig. 2 The testing apparatus

In order to obtain the shear stress-strain relations of sintered lap shear joints as the base for cyclic tests, a series of shear tests were conducted at four different ambient temperatures of $25^{\circ} \mathrm{C}, 225^{\circ} \mathrm{C}$, $275^{\circ} \mathrm{C}$ and $325^{\circ} \mathrm{C}$. For fatigue and dwell-fatigue tests, the loading conditions are listed in Table 1. 3 samples were conducted for each loading condition. All the shear and cyclic tests were conducted under stress-controlled mode with loading rate of $2 \mathrm{MPa} / \mathrm{s}$. 
Table 1. Loading conditions for low-temperature sintered nano-silver lap-shear joints

\begin{tabular}{ccccc}
\hline Name & $\begin{array}{c}\text { Temperature } \\
/{ }^{\circ} \mathrm{C}\end{array}$ & $\begin{array}{c}\text { Stress amplitude } \\
\text { /MPa }\end{array}$ & $\begin{array}{c}\text { Mean stress } \\
\text { /MPa }\end{array}$ & $\begin{array}{c}\text { Dwelling time } \\
/ \mathrm{s}\end{array}$ \\
\hline $\mathrm{A} 1$ & 325 & 10 & 0 & 0 \\
$\mathrm{~A} 2$ & 325 & 9 & 0 & 0 \\
$\mathrm{~A} 3$ & 325 & 8 & 0 & 0 \\
$\mathrm{~A} 4$ & 325 & 7 & 0 & 0 \\
$\mathrm{~A} 5$ & 325 & 6 & 0 & 0 \\
$\mathrm{~A} 6$ & 325 & 5 & 0 & 0 \\
$\mathrm{~A} 7$ & 325 & 6 & 0 & 1 \\
$\mathrm{~A} 8$ & 325 & 6 & 0 & 3 \\
$\mathrm{~A} 9$ & 325 & 6 & 0 & 5 \\
$\mathrm{~A} 10$ & 325 & 6 & 0 & 7 \\
$\mathrm{~A} 11$ & 325 & 6 & 0 & 9 \\
$\mathrm{~A} 12$ & 325 & 0 & 6 & 0 \\
$\mathrm{~B} 1$ & 225 & 10 & 0 & 0 \\
$\mathrm{~B} 2$ & 225 & 9 & 0 & 0 \\
$\mathrm{~B} 3$ & 225 & 8 & 0 & 0 \\
$\mathrm{~B} 4$ & 225 & 7 & 0 & 0 \\
$\mathrm{~B} 5$ & 225 & 7 & 0 & 1 \\
$\mathrm{~B} 6$ & 225 & 7 & 0 & 7 \\
$\mathrm{~B} 7$ & 225 & 7 & 0 & 9 \\
\hline
\end{tabular}

\section{Results and discussion}

\subsection{Shear behavior at elevated temperatures}

As shown in Fig.3, the effect of temperature on strain level of nano-silver joints can be concluded. At room temperature of $25^{\circ} \mathrm{C}$, the failure strain is less than $1.5 \%$, which contains a small part of plastic strain and thus a brittle failure. With the temperature increasing, the shear modulus is decreased and the plastic flow of the joint was more obvious. The average shear strength under 4 ambient temperatures is given in Fig. 4. When the temperature is higher than $225^{\circ} \mathrm{C}$, the shear strength drops dramatically, and almost halve at the temperature of $325^{\circ} \mathrm{C}(14 \mathrm{MPa})$. 


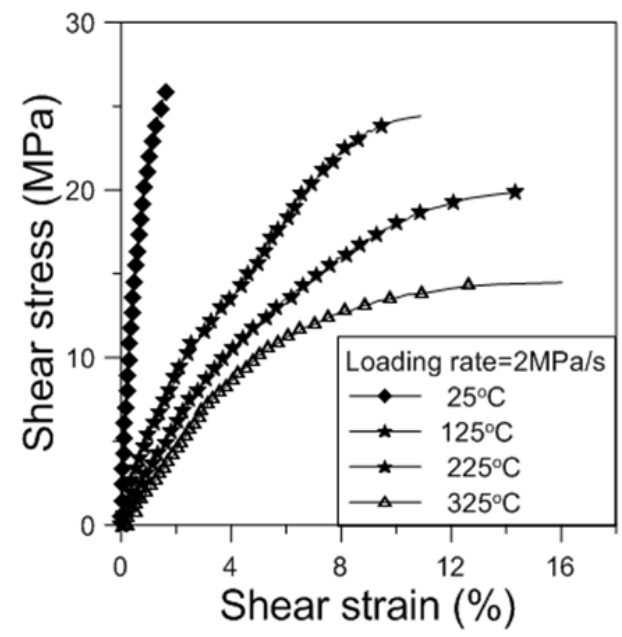

Fig.3 Shear stress-strain relationship of sintered nano-silver joint

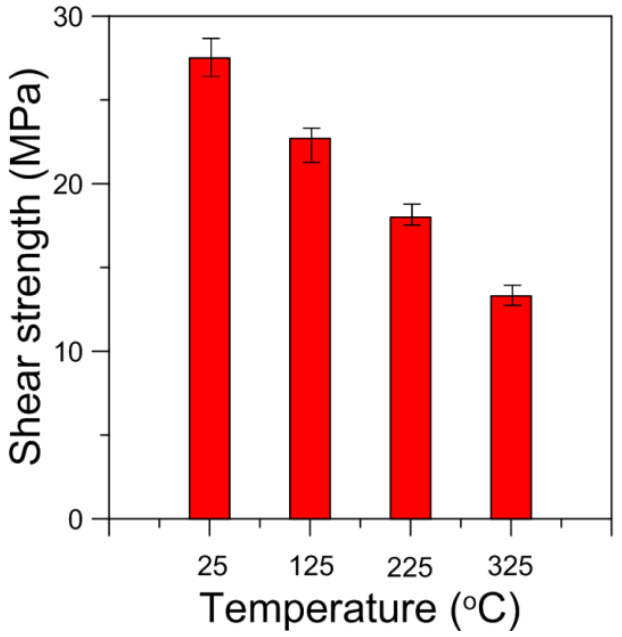

Fig.4 Shear strength of sintered nano-silver joint

3.2 Fatigue tests of fully reversed at elevated temperature

\subsubsection{Fatigue behavior}

Figure 5 shows shear stress-strain hysteresis loop under different loading amplitudes. From Fig. 5 we can find that the shear strain amplitude increases with the loading amplitude increasing under fully reversed loading situation. The increasing of hysteresis loops with loading amplitudes demonstrates the larger energy dissipating per unit volume during a cycle, which results in fewer cycles.

The plot of shear strain range versus number of cycles as shown in Fig.6 illustrates that the initial shear strain range increases as the increasing of the loading amplitudes. The evolution of shear strain range can be divided into three stages. The first stage has the longest duration of about 60-80 percent of the fatigue life and takes almost constant shear strain amplitude. When the fatigue test steps into the second stage of 80-90 percent of fatigue life, the shear strain slowly increases, which can be considered as the crack initiation. The final 10 percent of fatigue life is involving the third stage, during which the fatigue damage accumulation accelerates and results in ultimate failure.

The true strain-stress hysteresis loops of the nano-silver joint at load amplitude of $6 \mathrm{MPa}$ and 8MPa are displayed at Fig. 7. The enclosed area of the hysteresis loop represents the cyclic plastic energy consumed in each cycle. At certain loading amplitude, with the increasing of the cycles, the enclosing area increases gradually. The enclosed area of hysteresis loop experiences a rapid increase before the nano-silver joint comes to the final failure. 


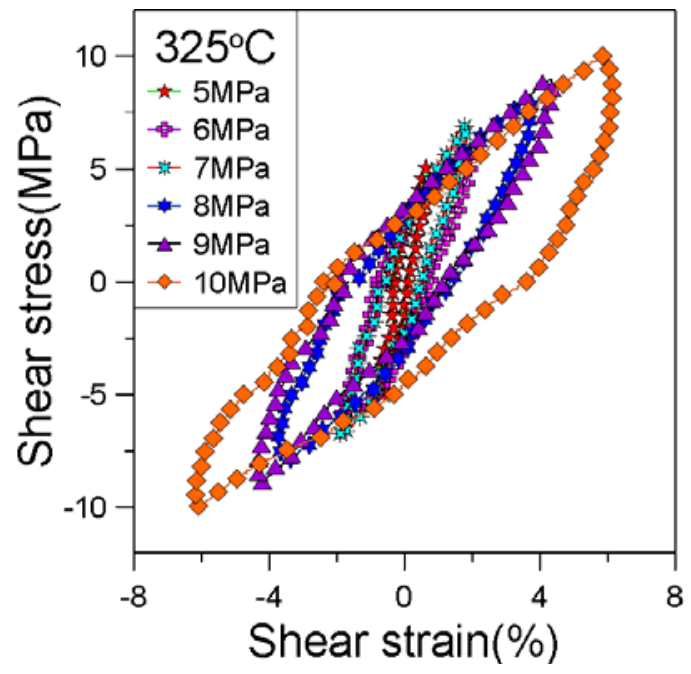

Fig. 5 Comparison of hysteresis loop under different loading amplitudes

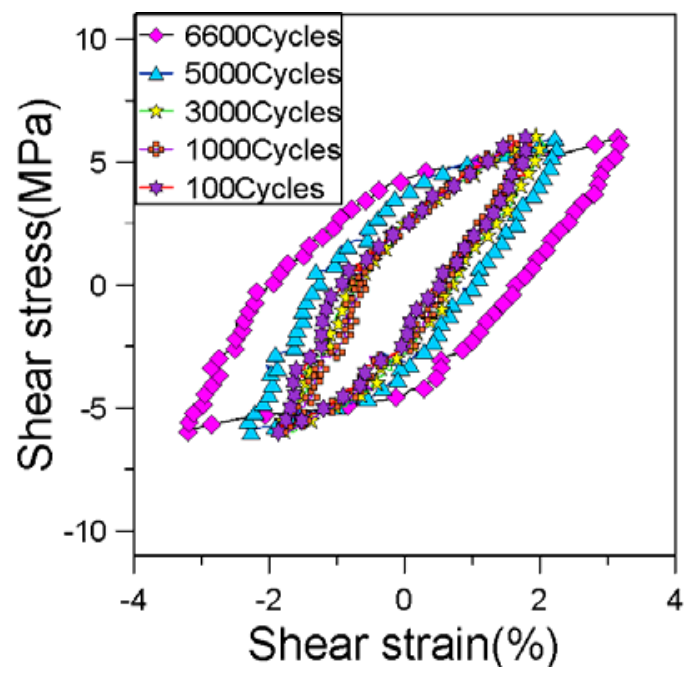

(a) At the loading amplitude of $6 \mathrm{MPa}$

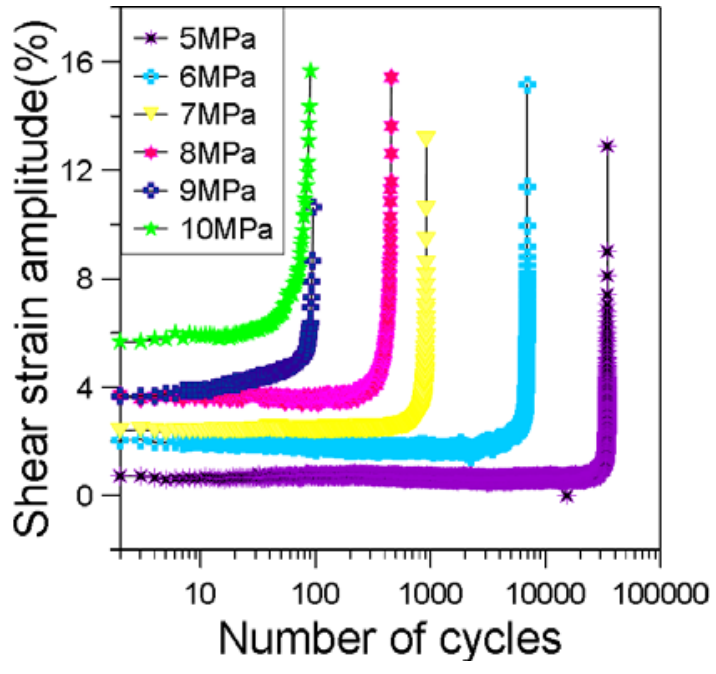

Fig. 6 Comparison of strain amplitude under different loading amplitudes at the temperature of $325^{\circ} \mathrm{C}$

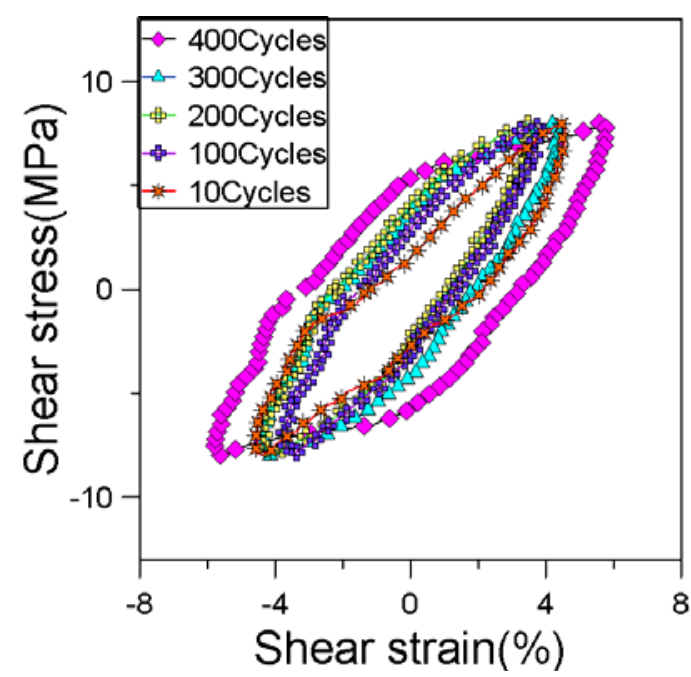

(b) At the loading amplitude of $8 \mathrm{MPa}$

Fig. 7 Comparisons of hysteresis loops under different cycles

The temperature effects on hysteresis loops under $7 \mathrm{MPa}$ and $9 \mathrm{MPa}$ loading amplitude are shown in Fig. 8. It can be found that at higher temperature of $325^{\circ} \mathrm{C}$, more plastic strain is present and the loops are wider, which causes the cyclic plastic deformation in the joint to be more severe. As a result, the fatigue life at the temperature of $325^{\circ} \mathrm{C}$ is shorter than that at the temperature of $225{ }^{\circ} \mathrm{C}$. It should not be ignored that higher temperature could mobilize the dislocation of the nano-silver joints, which leads to a significant reduction of fatigue life. 


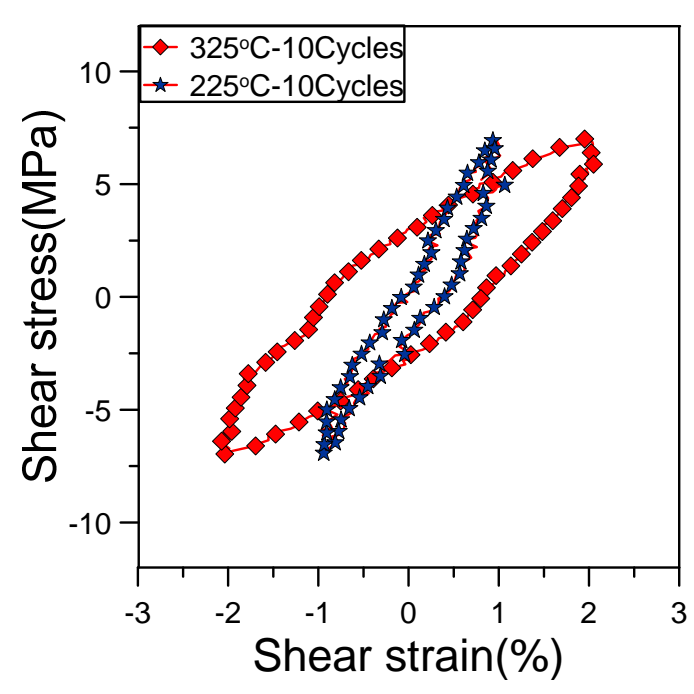

(a) At the loading amplitude of $7 \mathrm{MPa}$

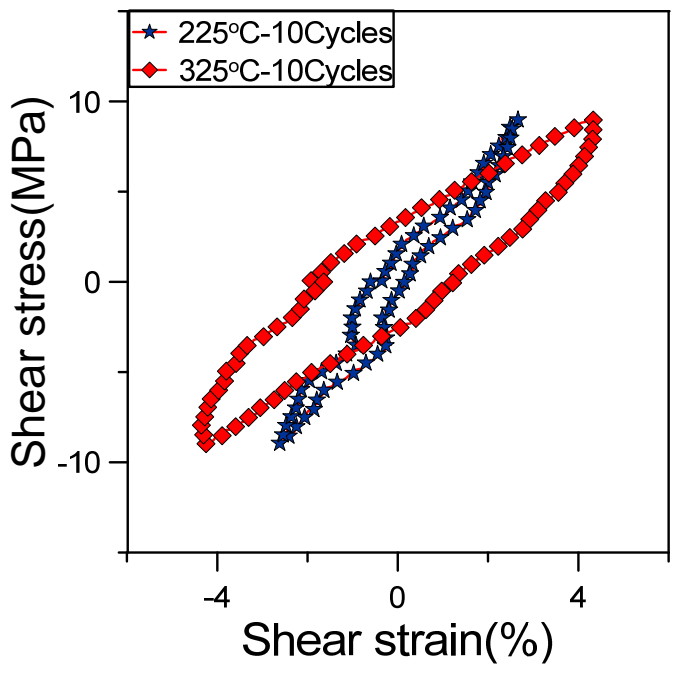

(b) At the loading amplitude of $9 \mathrm{MPa}$

Fig. 8 Comparison of the hysteresis loops at the temperature of $325^{\circ} \mathrm{C}$ and $225^{\circ} \mathrm{C}$

\subsubsection{Fatigue life prediction}

The stress-life (S-N) data can be plotted linearly in a log-log scale which is firstly observed by Basquin [12]. Here the formula can be expressed as

$$
\Delta \tau / 2=\sigma_{f t}^{\prime}\left(2 N_{f}\right)^{b}
$$

The relationship between the shear stress amplitude and the fatigue life for sintered nano-silver lap shear joint at $325^{\circ} \mathrm{C}$ and $225^{\circ} \mathrm{C}$ are linearly fitted as Basquin's equation in the logarithm coordinate system as shown in Fig. 9. The fatigue strength exponent $b$ and fatigue strength coefficient $\sigma_{f t}^{\prime}$ for sintered lap shear joint are given in Table 2. It can be obviously observed that the fatigue strength coefficient increased with decreasing temperature. The fatigue strength exponent has little change at different temperature as is shown in Fig. 9. The fatigue life of the nano-silver sintered lap-shear joints at the temperature of $325^{\circ} \mathrm{C}$ and $225{ }^{\circ} \mathrm{C}$ are fitted well.

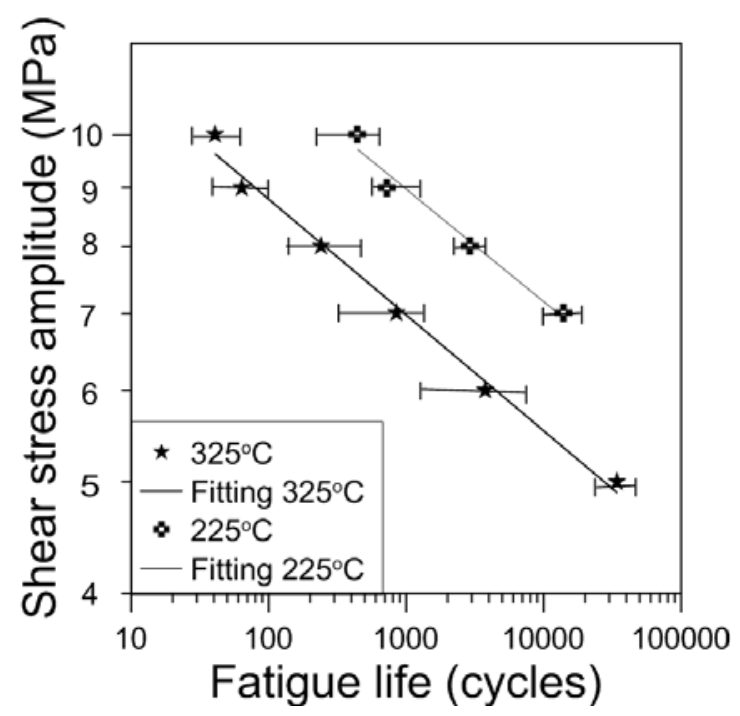

Fig. 9 S-N curve for nano-silver sintered lap-shear joints 
Table 2. Comparison of fatigue properties between experimental value and empirical value

\begin{tabular}{ccc}
\hline Temperature $\left({ }^{\circ} \mathrm{C}\right)$ & $\sigma_{f t}^{\prime}$ & $B$ \\
\hline 225 & 19.2 & -0.1056 \\
325 & 15.3 & -0.1061 \\
\hline
\end{tabular}

3.3 The dwell-fatigue behavior of nano-silver sintered lap-shear joints

As listed in Table 2, a series of dwell-fatigue tests (A7-A11) are conducted at the loading amplitude of $6 \mathrm{MPa}$ and the temperature of $325^{\circ} \mathrm{C}$. From the results show in Table 3 we can find that with the increasing of dwell time, the fatigue life in cycle decreases at a rapid rate. But the total creep time (dwell time summation) holds between 2000-4000s, which indicates that the creep take a more important part in the failure process and might lead to the final failure. A point should be put forward that dwell sensitivity accelerates the fatigue failure while the cyclic loading prolong the creep life, since the creep life of the joints under the same loading amplitude is only $415 \mathrm{~s}$.

Table 3. The dwell-fatigue tests data under different dwell time.

\begin{tabular}{ccccc}
\hline Spec. ID & $\begin{array}{c}\text { Temperature } \\
/{ }^{\circ} \mathrm{C}\end{array}$ & $\begin{array}{c}\text { Dwell time } \\
(\mathrm{s})\end{array}$ & $\begin{array}{c}\text { Fatigue Life } \\
\text { (cycles) }\end{array}$ & $\begin{array}{c}\text { Total creep Time } \\
(\mathrm{s})\end{array}$ \\
\hline A6 & 325 & 0 & 6925 & 0 \\
A7 & 325 & 1 & 2538 & 2538 \\
A8 & 325 & 3 & 1226 & 3678 \\
A9 & 325 & 5 & 438 & 2180 \\
A10 & 325 & 7 & 536 & 3752 \\
A11 & 325 & 9 & 239 & 2151 \\
B4 & 225 & 0 & 9800 & 0 \\
B5 & 225 & 1 & 4590 & 4590 \\
B6 & 225 & 7 & 919 & 6433 \\
B7 & 225 & 9 & 409 & 3681 \\
\hline
\end{tabular}

Fig.10 indicates that the number of cycles verses dwell time is a straight line on the semi-log plot. The life in cycles reduces with the increasing of dwell time. It should be pointed out that the effect of dwell time at the temperature of $325^{\circ} \mathrm{C}$ is more significant than that of $225^{\circ} \mathrm{C}$. In other words, as the creep behavior of nano-silver sintered lap-shear joints is significantly influenced by temperature, so creep plays a more important part to the final failure of specimens at the temperature of $325^{\circ} \mathrm{C}$ than $225^{\circ} \mathrm{C}$. However, a series of creep-fatigue tests need to be conducted for further study of the effect of creep on creep-fatigue tests. 


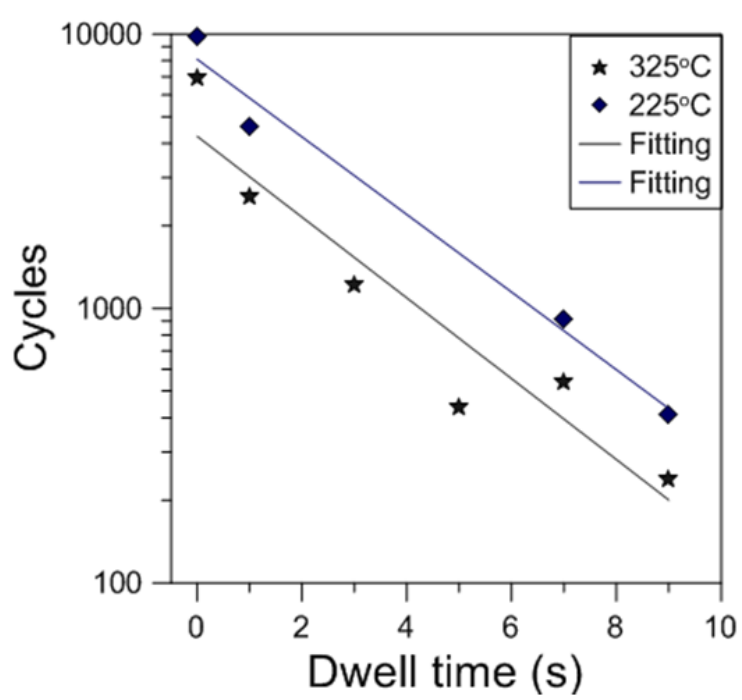

Fig.10 The fatigue data with different dwelling time

\section{Conclusions}

Firstly, the shear tests of nano-silver sintered lap-shear joints at elevated temperatures were conducted to study the effect of temperature on shear behavior. Secondly, a series of fatigue tests under fully reversed loading indicated how temperature affected the Basquin equation. Finally, the effect of creep on fatigue was studied at high temperature of $325{ }^{\circ} \mathrm{C}$. The following conclusions are obtained.

(1) Shear behaviors are temperature dependent. The shear strength decreases with the increased of temperature. The shear strength at room temperature is as high as $28 \mathrm{MPa}$, which halve at the temperature of $325^{\circ} \mathrm{C}$.

(2) Basquin s equation is presented to predict the fatigue life of the nano-sintered lap-shear joints at different temperatures, where the fatigue strength exponent $b$ is a constant and the fatigue strength coefficient $\sigma_{f t}^{\prime}$ is a value dependent on temperature, which decreases with the elevated temperature

(3) With the increasing of the dwell time, the effect of creep becomes more and more significant. It can be concluded from the dwell-fatigue tests at the temperature of $325^{\circ} \mathrm{C}$ that creep is the main factor that lead to the final failure of the specimen.

\section{Acknowledgements}

The project was supported by NSFC (No. 10802056 and No.11072171).

\section{References}

[1] L. Nie, M. Osterman, FB. Song, J. Lo, SWR. Lee, M. Pecht, Solder ball attachment assessment of reballed plastic ball grid array packages. IEEE translations on components and packaging, 32 (2009) 901-908.

[2] T. Wang, X. Chen, G.Q. Lu, G. Lei., Low-temperature sintering with Nano-silver paste in DieAttached interconnection. Journal of electronic materials, 36 (2007) 1333-1340 
[3] O'brien M, Rice C. R., Olson D. L., High strength diffusion welding of silver coated base metals. Welding Journal, 55 (1976) 25-27.

[4] Z. Zhang, G. Q. Lu, Pressure-assisted low-temperature sintering of silver paste as an alternative die-attach solution to solder reflow. IEEE translations on Electronics Packaging manufacturing, 25 (2002) 279-283.

[5] M. Knoerr, S. Kraft, A. Schlitz, Reliability assessment of sintered nano-silver die-attachment for power semiconductors, In: Proceedings of the Electronics Packaging Electronics Packaging Technology Conference (EPTC), 2010, pp. 56- 61.

[6] J.G. Bai, G. Q. Lu, Thermo mechanical Thermo mechanical reliability of low-temperature sintered tired silver die-attached SiC power device assembly. IEEE translations on Device Mater. Reliability, 6(2006) 436-441.

[7] T. Wang; X. Chen, G. Q. Lu.; Lei, G.; Low-Temperature sintering with Nano-silver paste in Die- Attached interconnection. Journal of electronic materials, 36(2007) 1333-1340

[8] D. J. Yu, X. Chen, G. Chen, G. Q. Lu; Applying Anand model to low-temperature sintered nano-scale silver paste chip attachment. Materials and design, 30(2009) 4574-4579

[9] G. Chen, X. H. Sun, P. Nie, X. Chen, G. Q. Lu, High-Temperature Creep Behavior of Low-Temperature-Sintered Nano-Silver Paste Films. Journal of electronic materials, 41(2012) $782-790$

[10] X. Li, G. Chen, X. Chen, Mechanical property evaluation of nano-silver paste sintered joint using lap-shear test, Soldering \& surface mount technology, 24(2012) 120-126

[11] X. Li, G. Chen, X. Chen, High temperature ratcheting behavior of nano-silver paste sintered lap shear joint under cyclic shear force, Microelectronics Reliability, 2012 in press

[12] Julie A. Bannantine, Jess J. Corner, James L. Handrock, Foundamentals of metal fatigue analysis, Prentice Hall press, New Jersey, 1990. 